\title{
Integrating microbial community data with ecological theory
}

Steve Allison

UC Irvine

Ecology and Evolutionary Biology

Earth System Science

allisons@uci.edu 


\section{What controls C stability?}

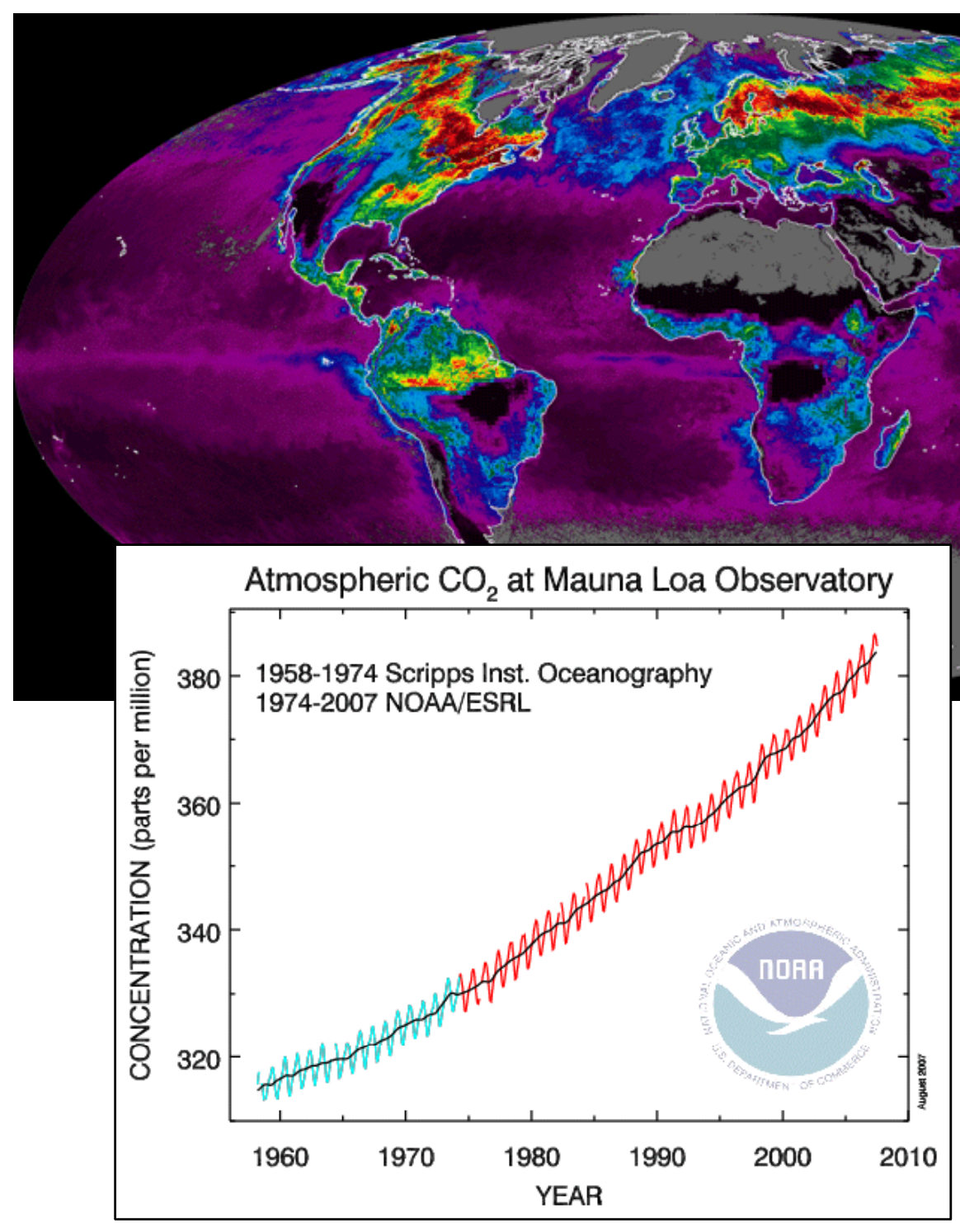

Ocean: 1000 Pg

Terrestrial: 2000+ Pg
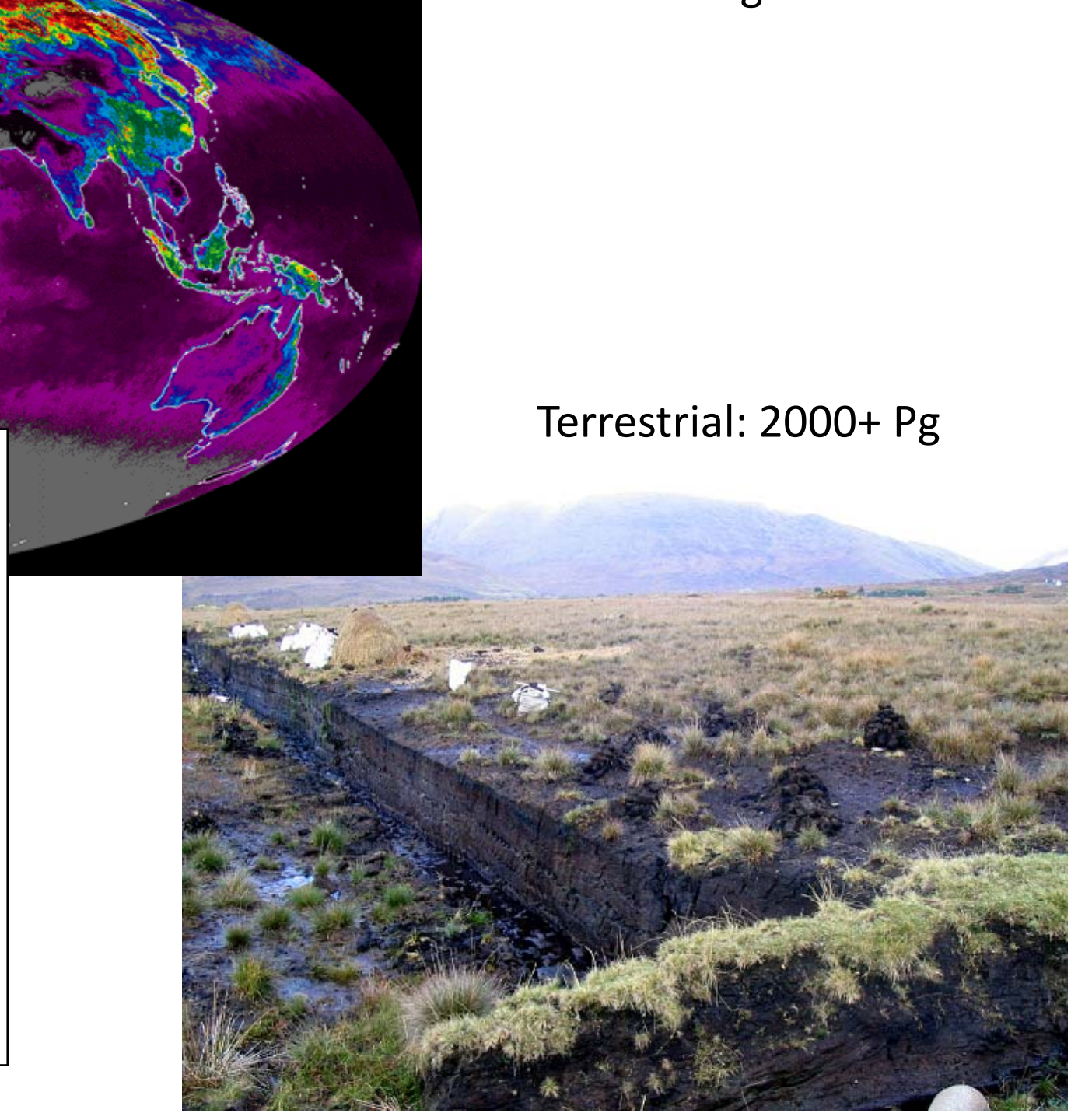


\section{Extracellular enzymes}

- Degrade complex molecules from plants, animals, and other microbes

- Ecosystem consequence: prevent the world from filling with dead bodies

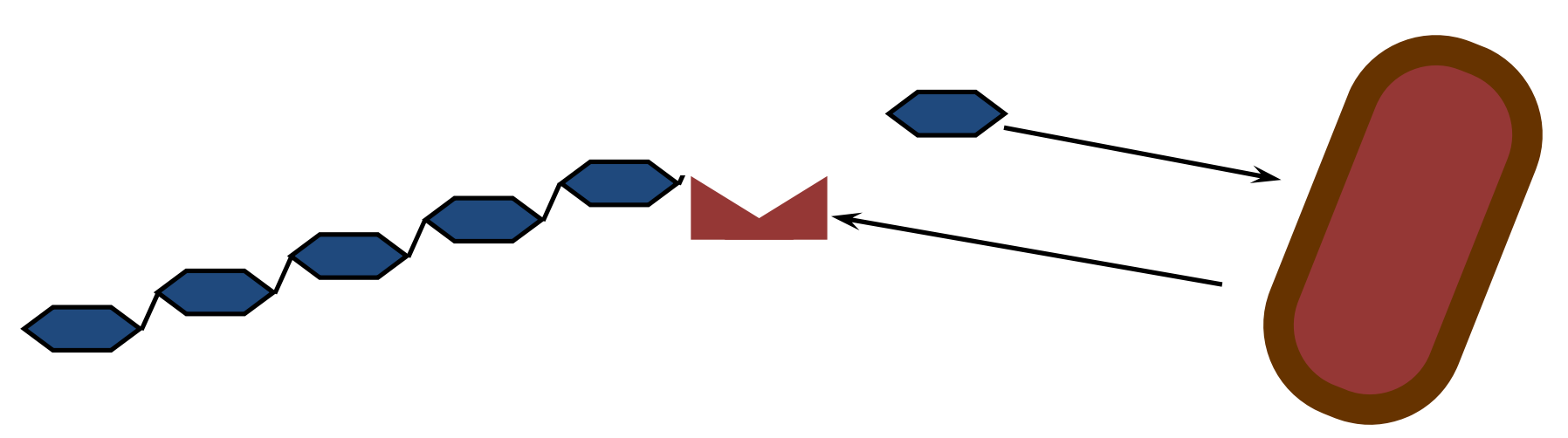




\section{Enzyme-based warming model}

sensu Schimel and Weintraub, 2003

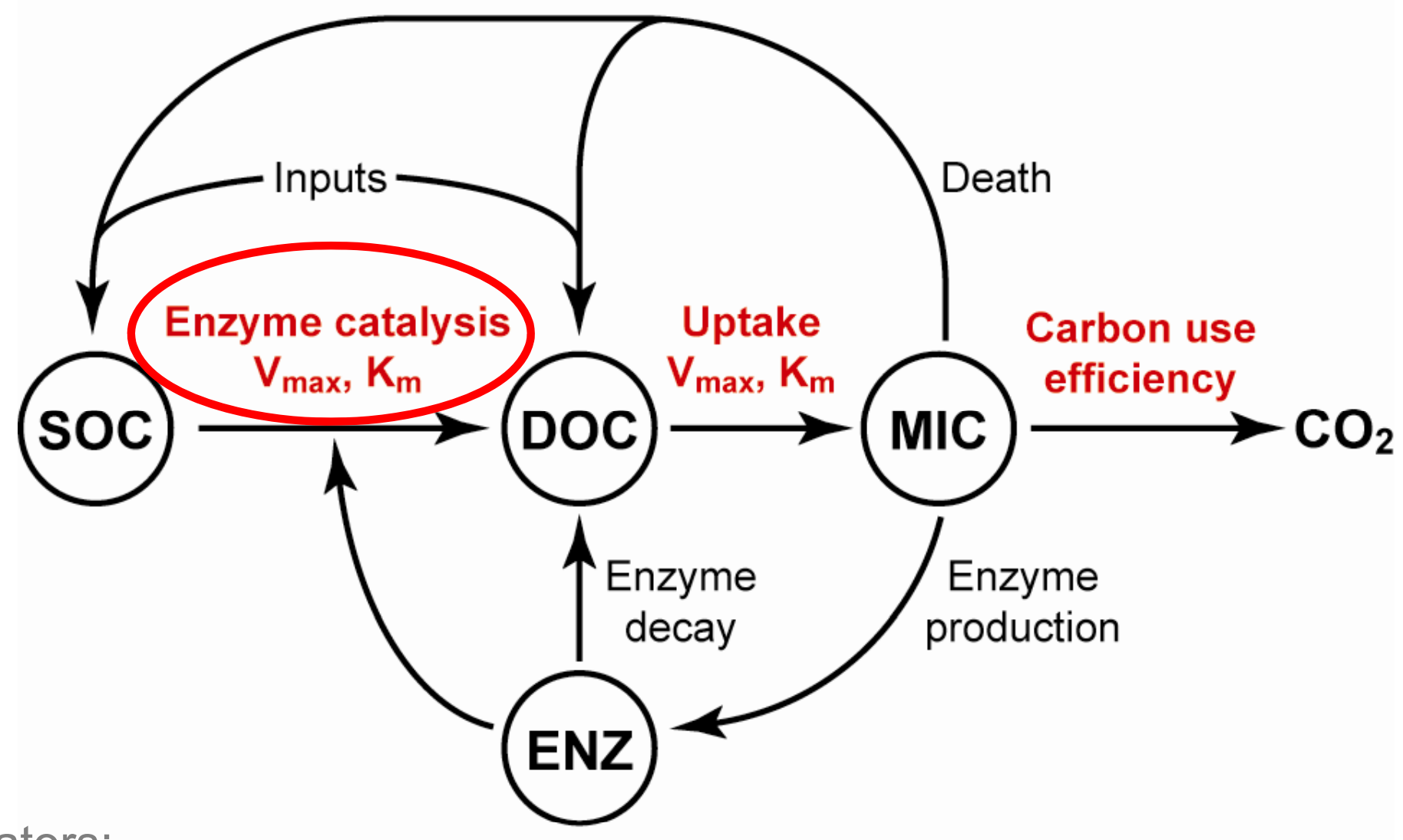

Collaborators:

Mark Bradford

Matt Wallenstein

Allison et al. 2010, Nature Geosci 


\section{How do we model enzyme response to warming?}

- Michaelis-Menten relationship

- Exponential increase in Vmax (Davidson \& Janssens 2006)

- Km response unknown in soil

- Models can drive experiments!

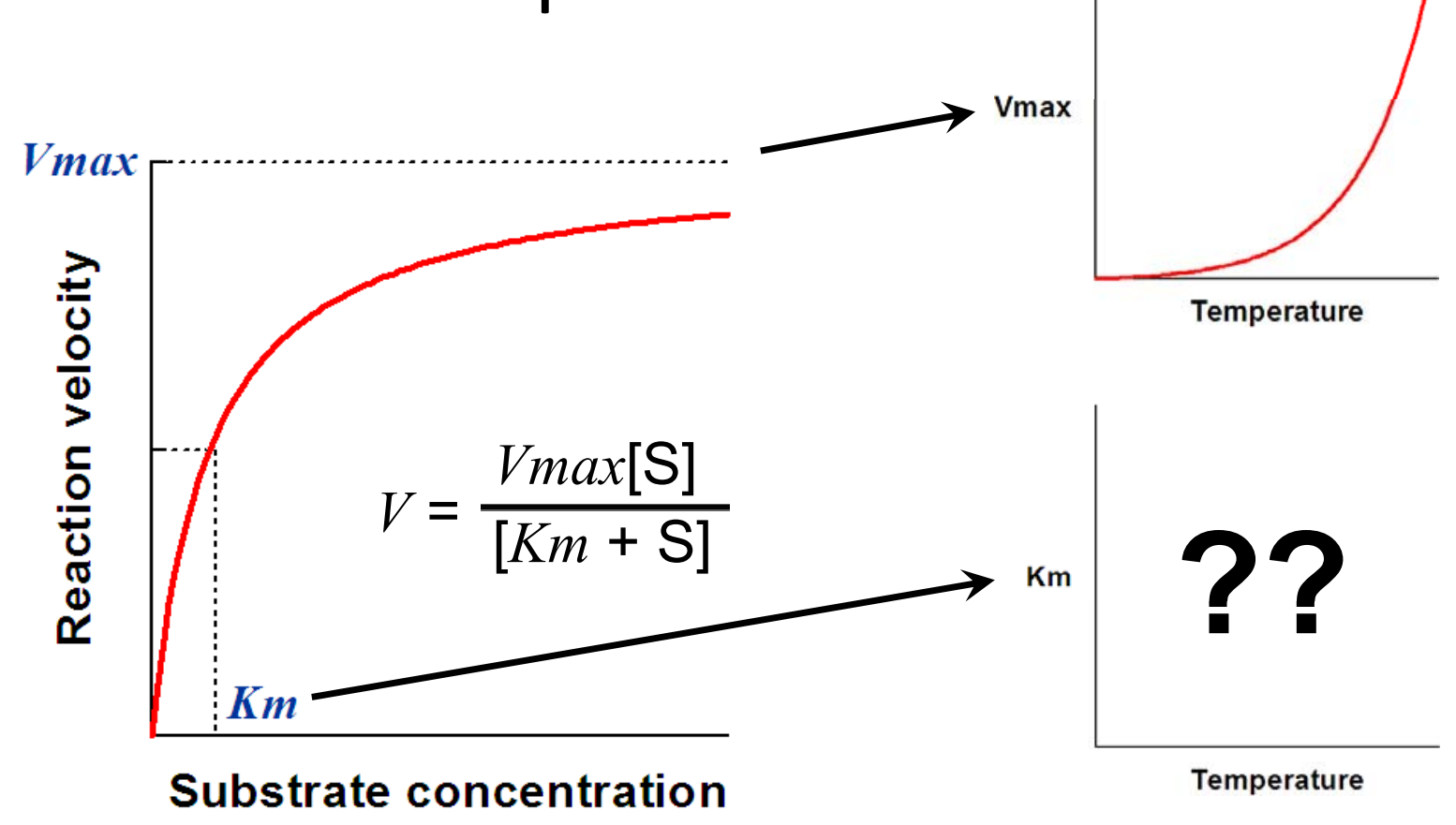




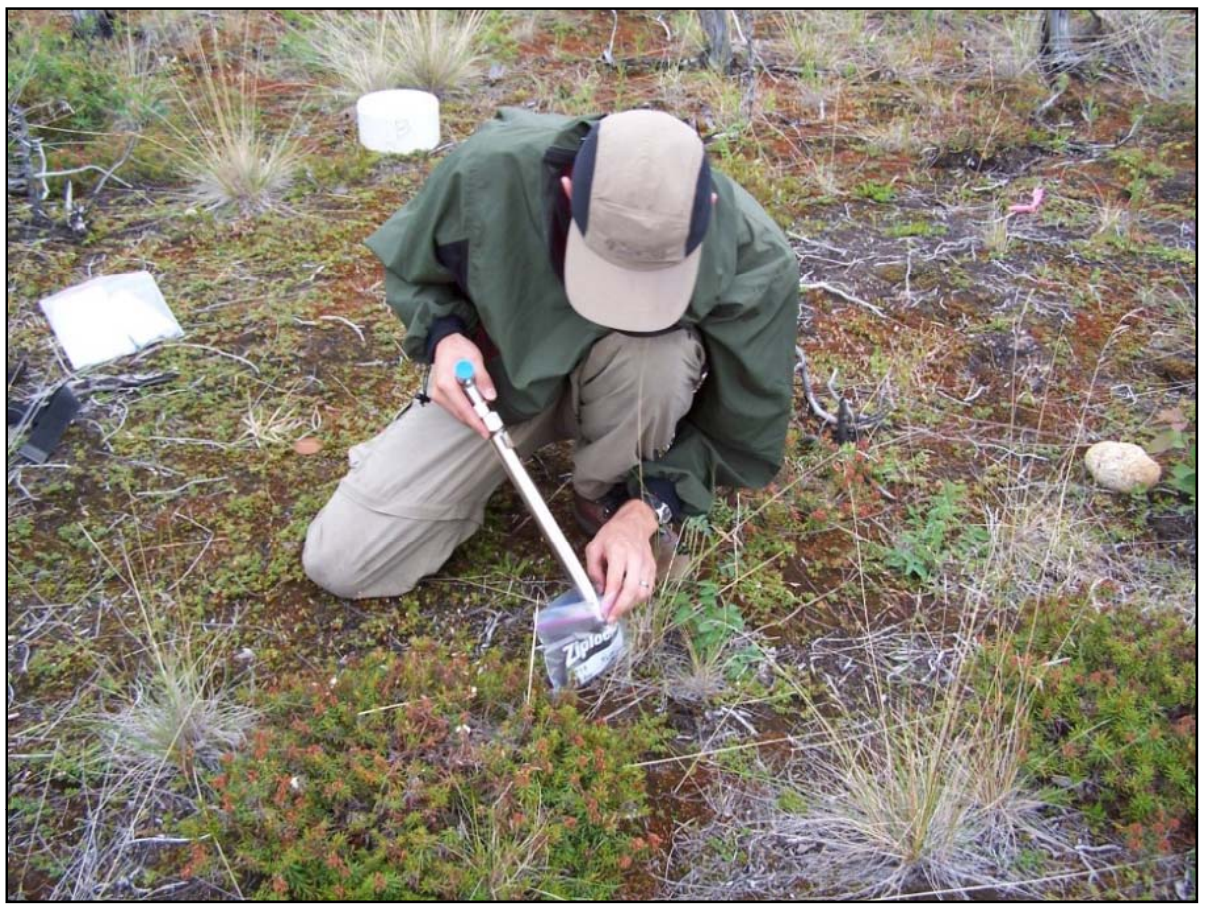

Soil sampling

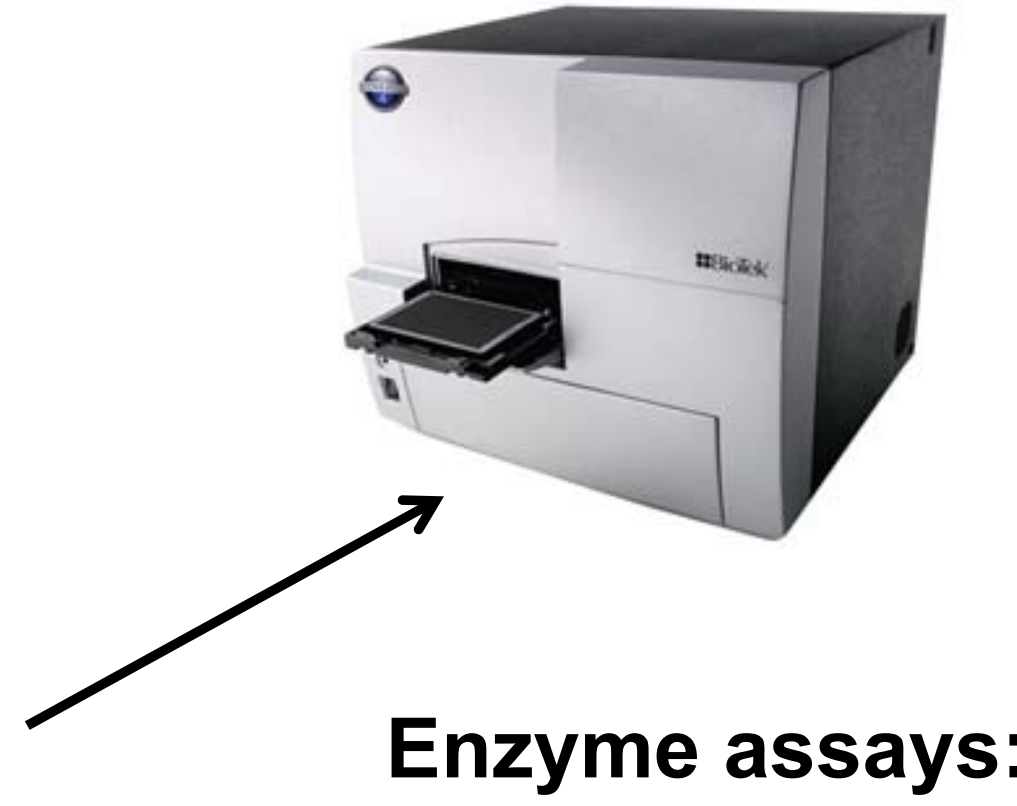

Maddie Stone

Kathleen Marcelo Stephany Chacon Donovan German

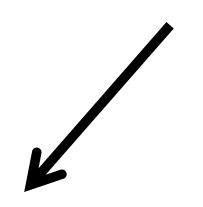

Temperature response:

Assay activity at $4^{\circ} \mathrm{C}$ to $40^{\circ} \mathrm{C}$ 


\section{What if microbes adapt to warming?}

- Return toward initial state due to physiology, evolution, community shifts

1) Vmax might increase less than expected with warming -> reduces enzyme activity

2) $\mathrm{Km}$ might change less than expected (declines in $\mathrm{Km}$ INCREASE activity) 


\section{Latitudinal gradient}






\section{Vmax temp. response within sites: Beta-glucosidase}
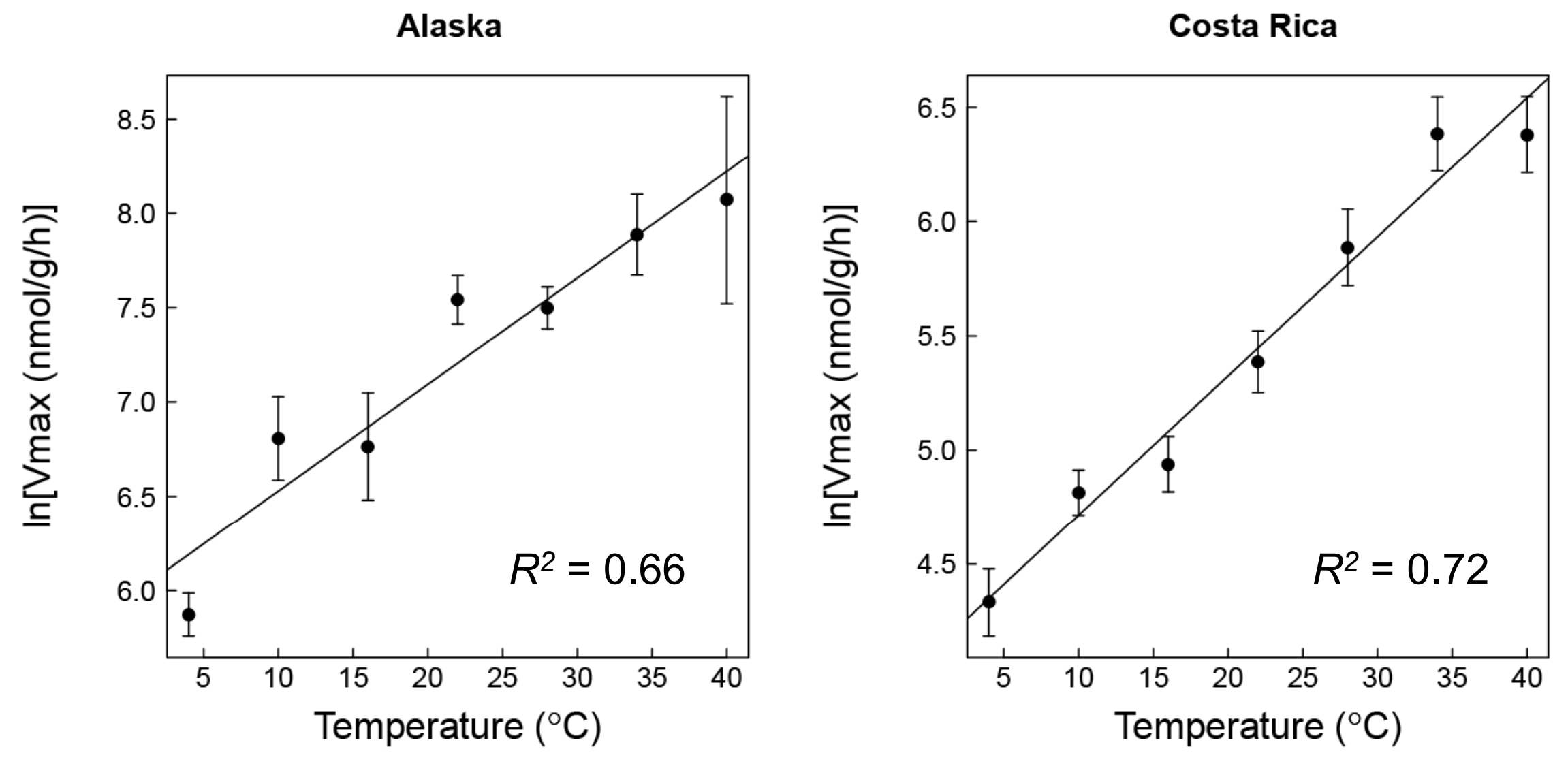


\section{No evidence for Vmax adaptation}

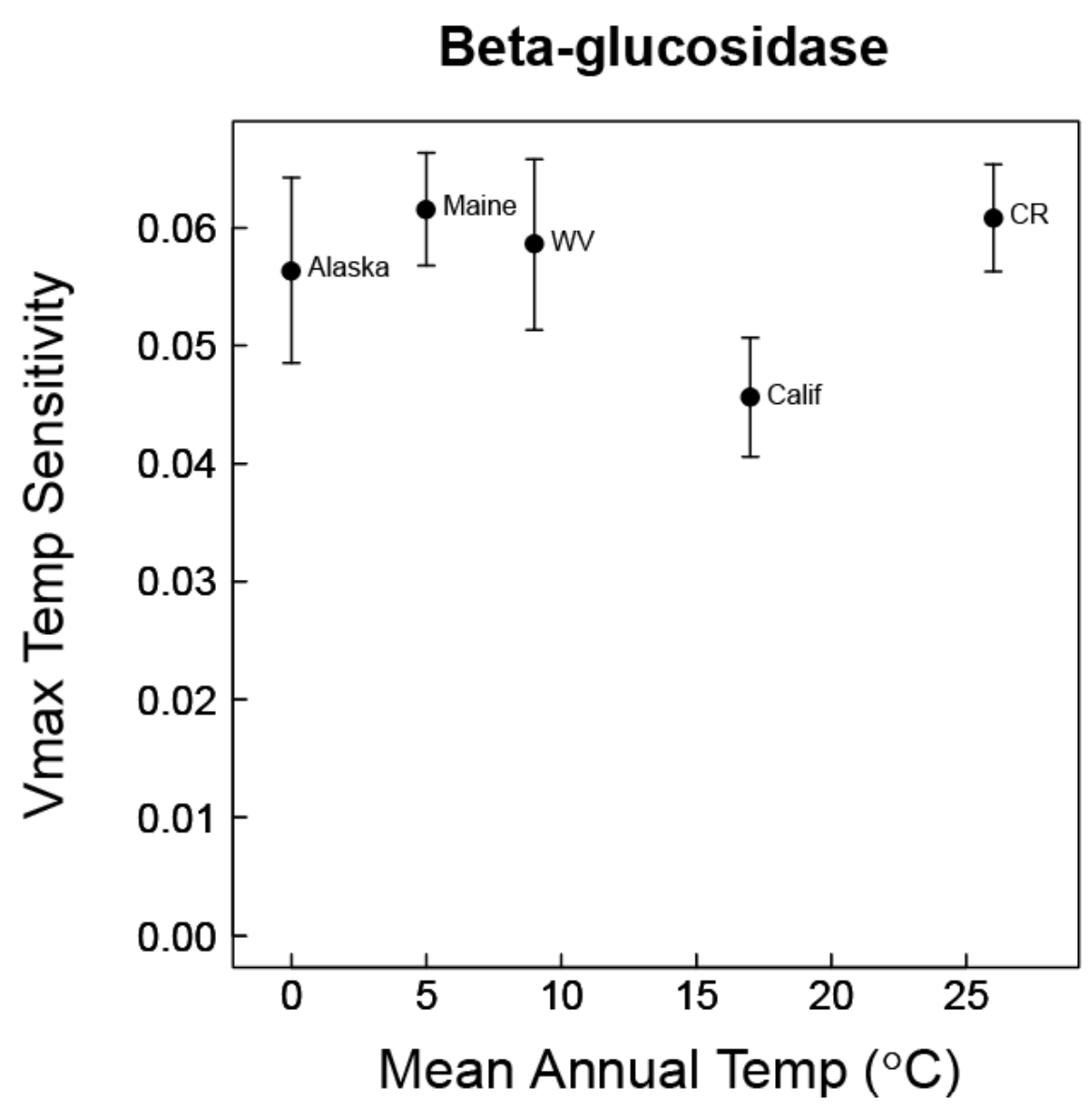




\section{$\mathrm{Km}$ temp. response within sites: Beta-glucosidase}
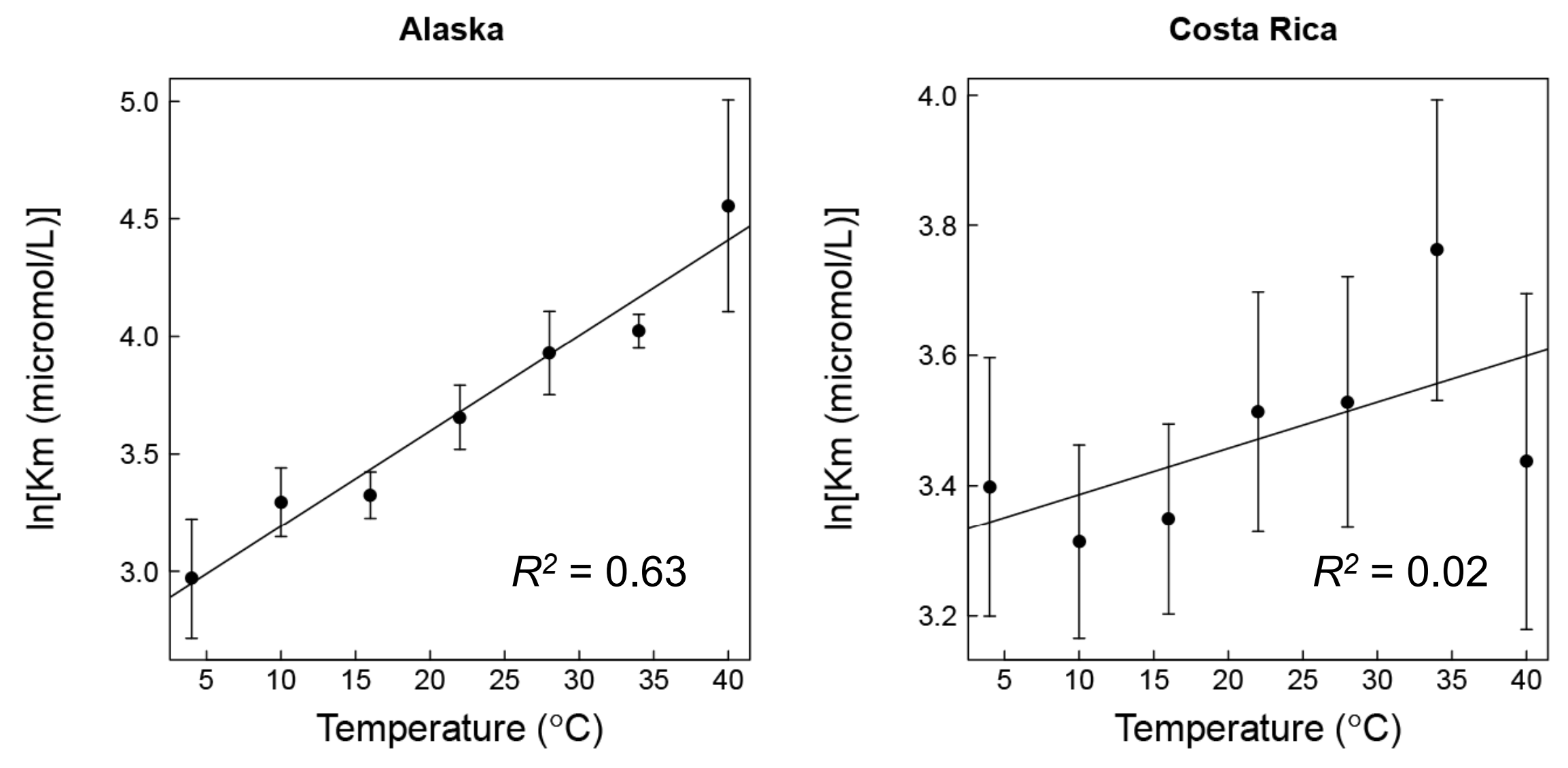


\section{Possible $\mathrm{Km}$ adaptation}

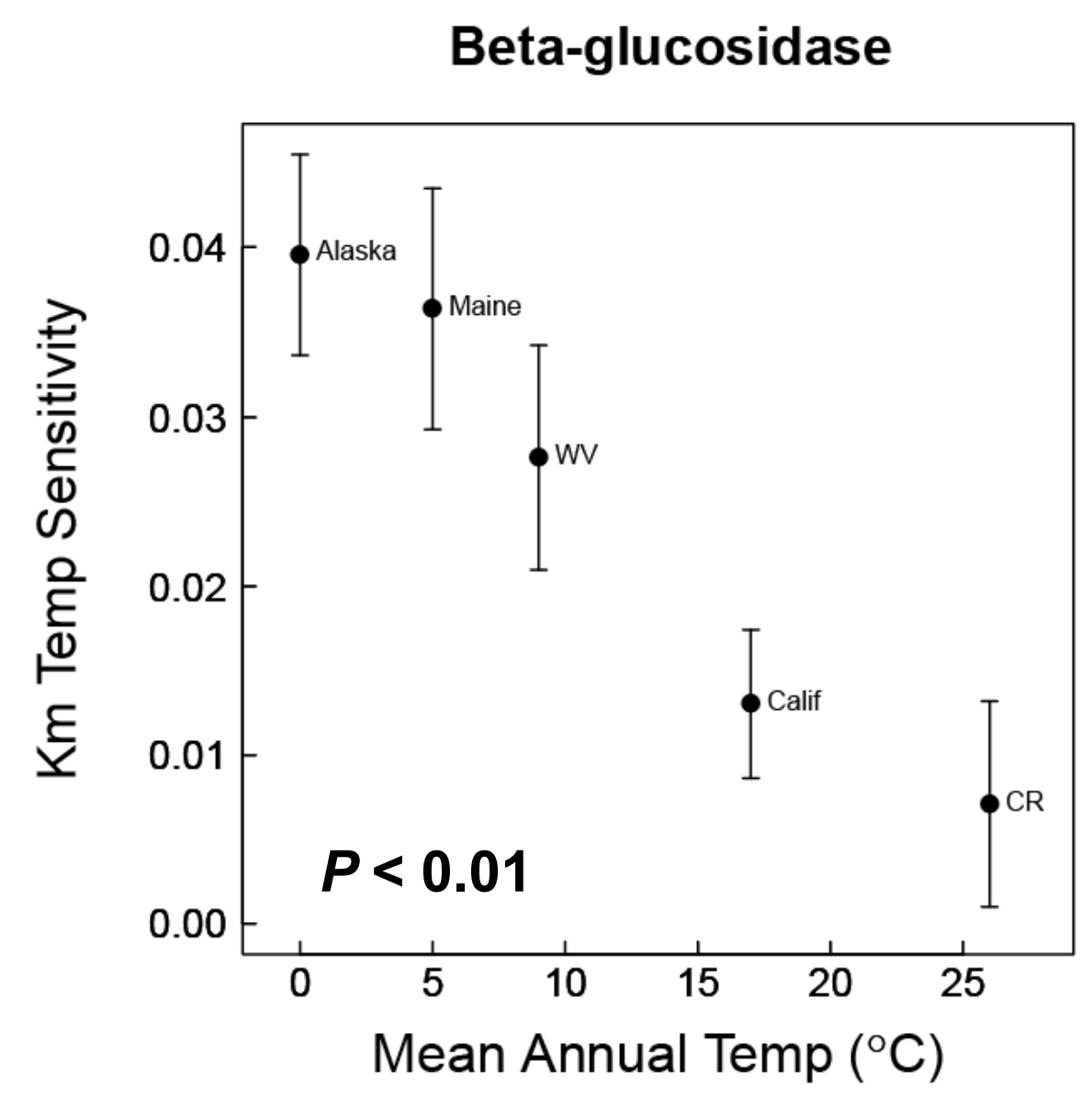




\section{Integrate theory and data into model}

$\mathrm{Km}$ adaptation: lose SOC

Vmax adaptation: gain SOC
Control

Warming

Warm+Km Adapt

Warm+Vmax Adapt

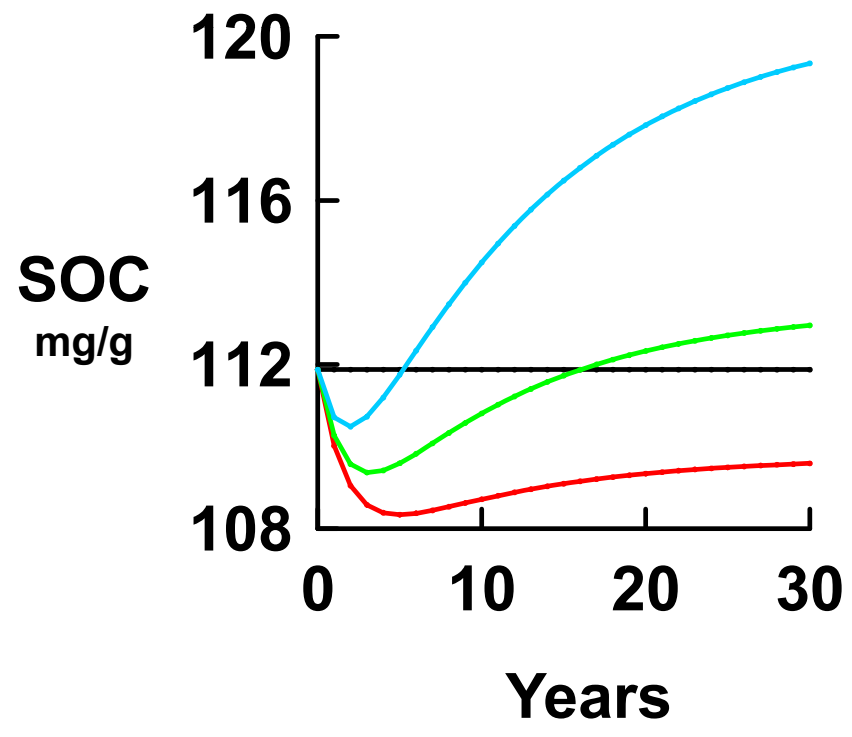




\section{Integrate theory and data into model}

$\mathrm{Km}$ adaptation: lose SOC

Vmax adaptation: gain SOC
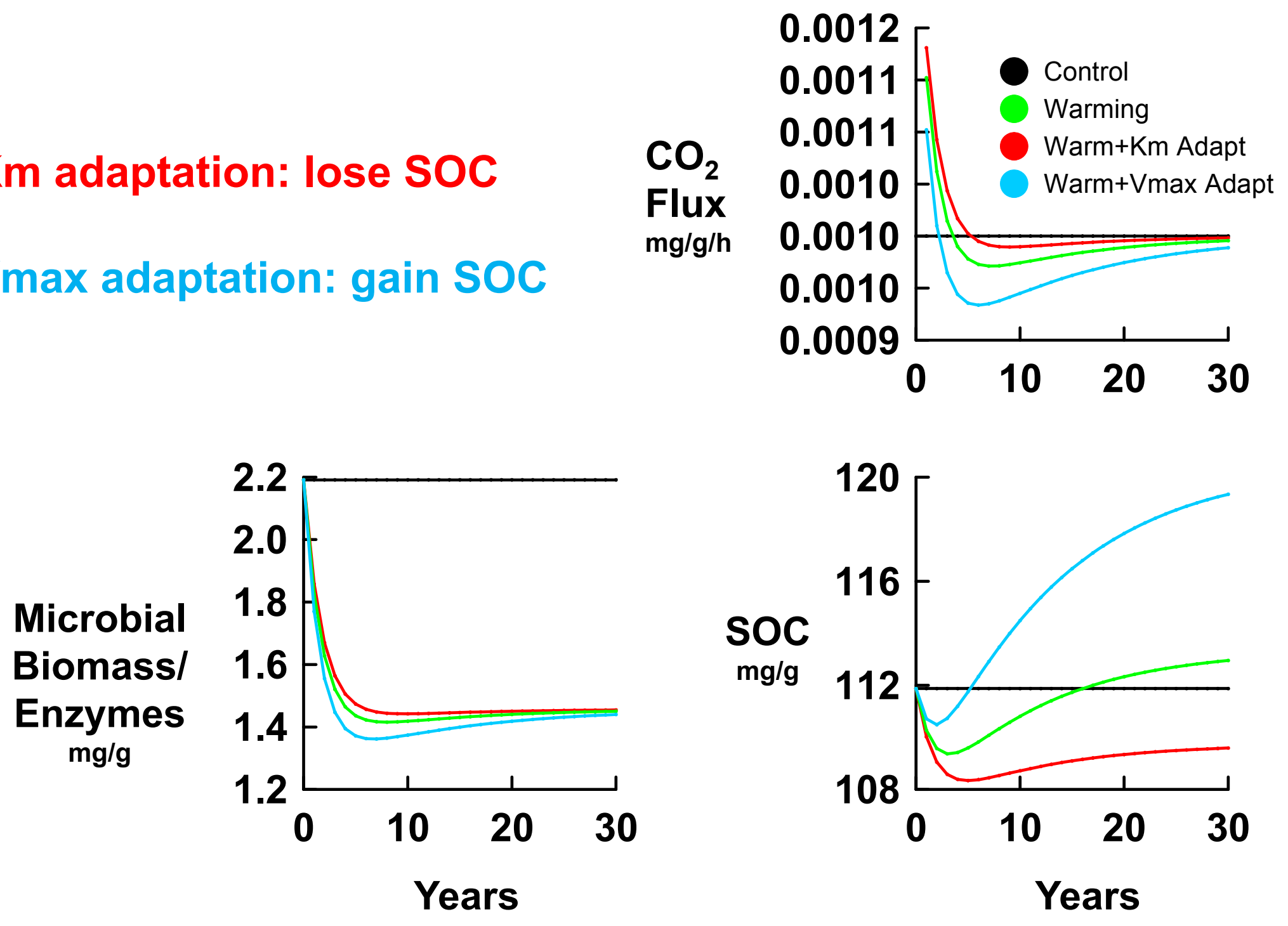

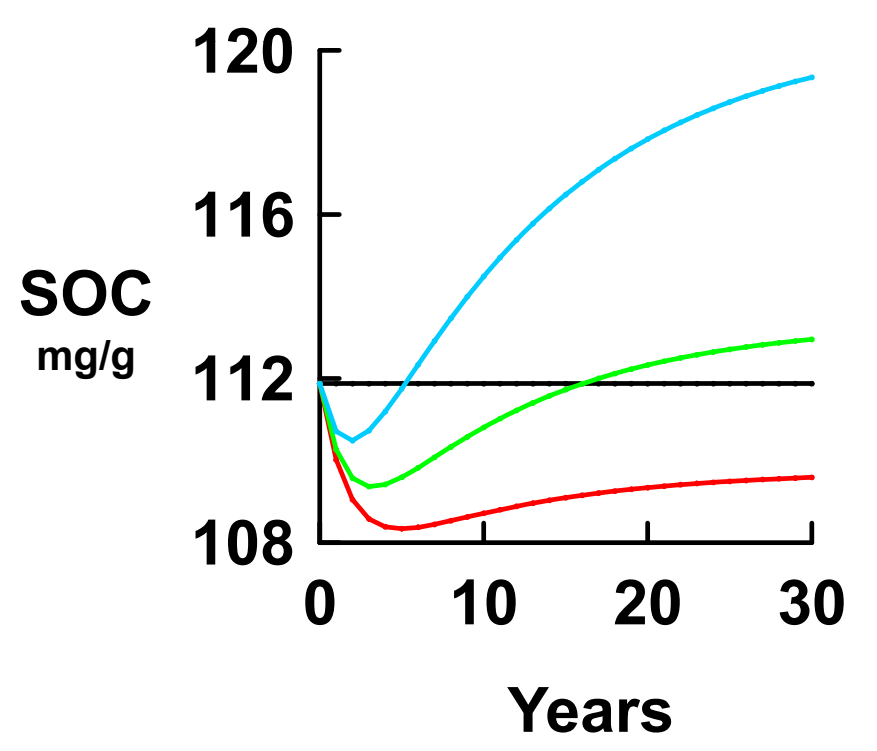




\section{Summary: Temperature responses}

- Vmax increases with temperature

- No Vmax adaption: no advantage to reducing enzymatic potential in warm soils

- $\mathrm{Km}$ also increases with temperature; substrate binding weakens due to instability

- Km may adapt because lower Km in warmer soil enhances enzyme activity 


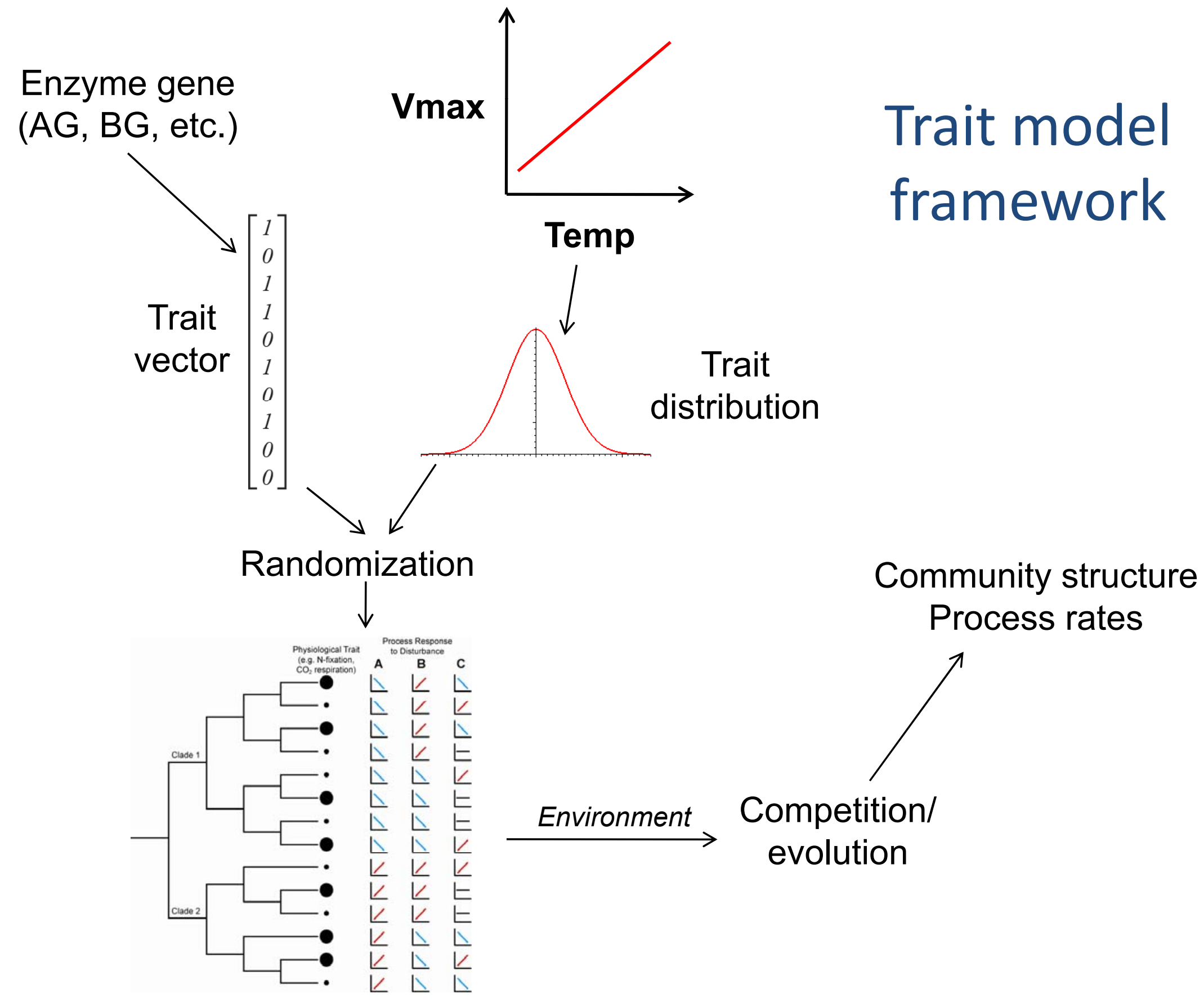




\section{Approach for model-data integration}

- For a process of interest, determine relevant traits and environmental drivers

- Constrain trait distributions with empirical data

- Sample trait distributions or assign functional groups in model

- Let the environment select on community and process

- Thank you: Lab members, NSF, audience 


\section{Constant CUE $=$ large SOC losses}

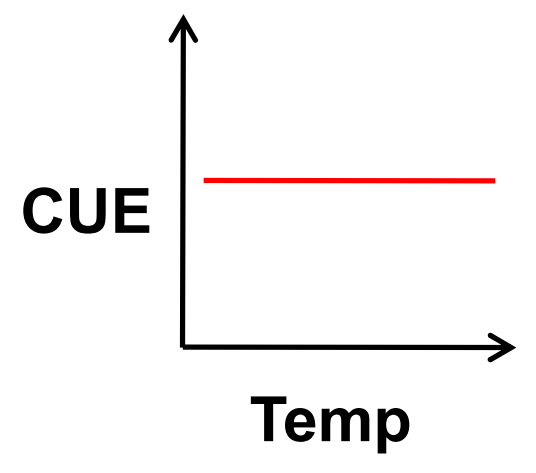

Control

Warm+Const CUE

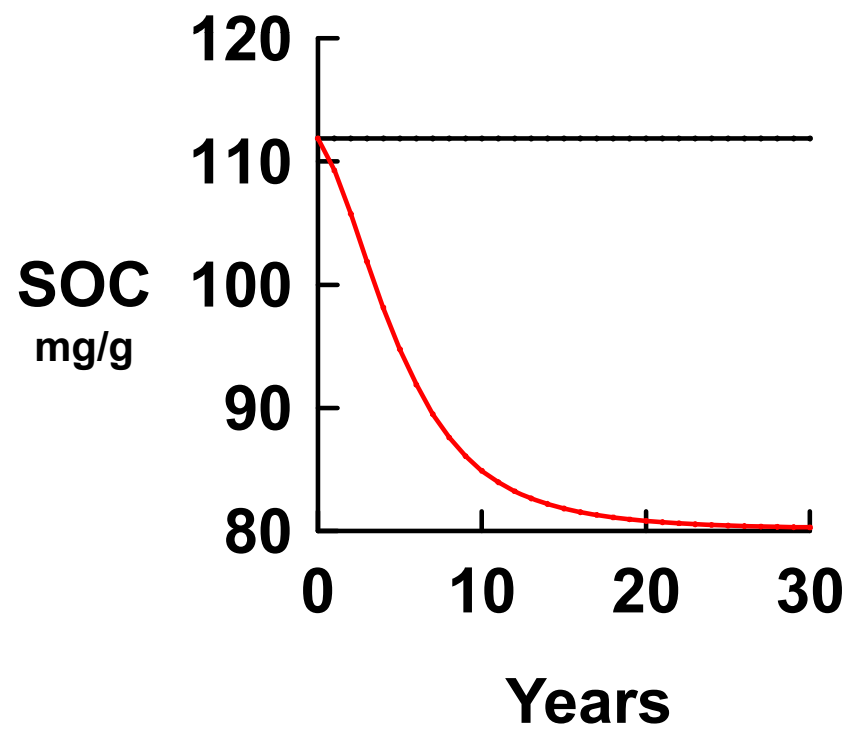




\section{Constant CUE $=$ large SOC losses}

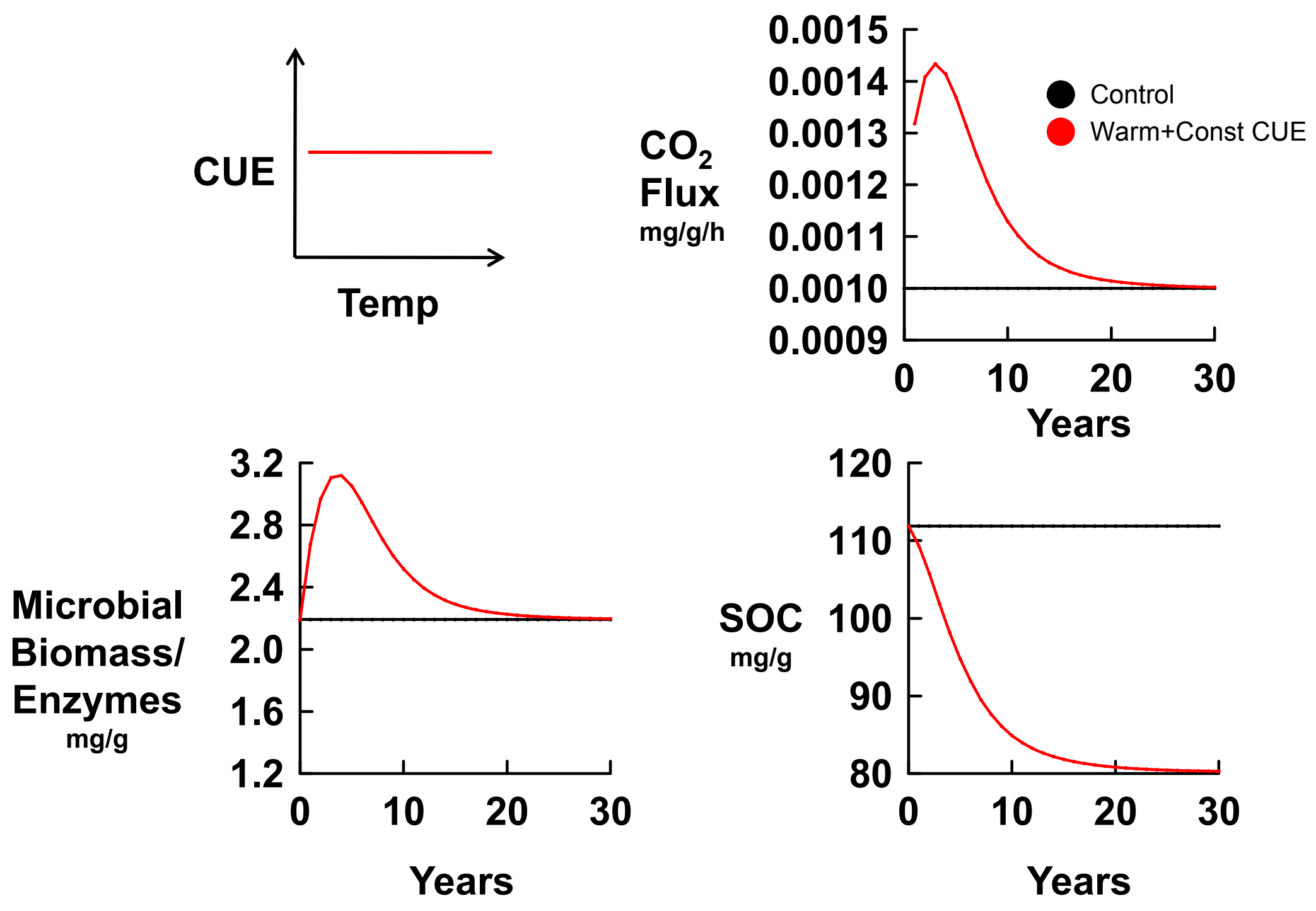




\section{Varying CUE increases C storage}
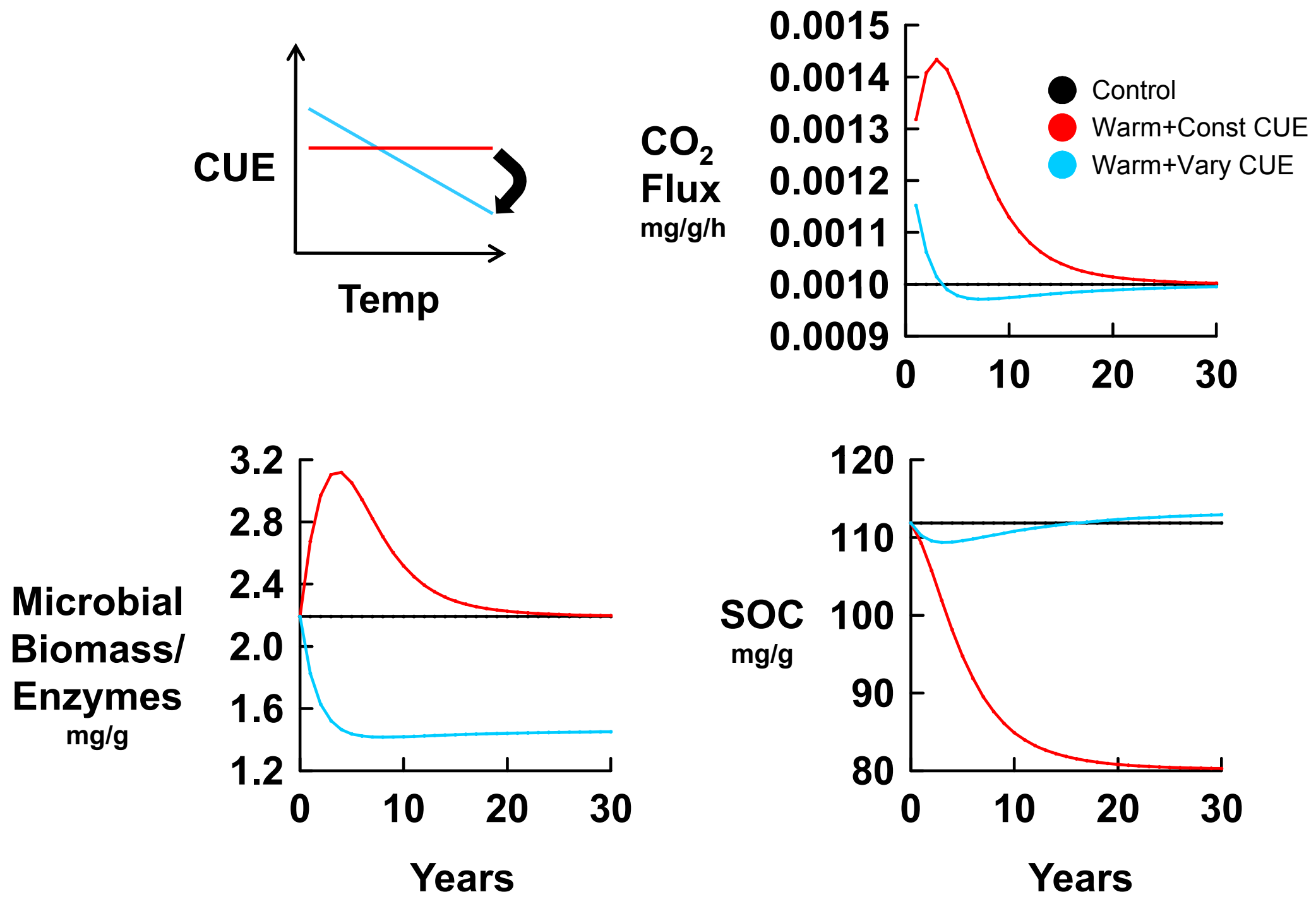


\section{Acclimation of CUE restores losses}
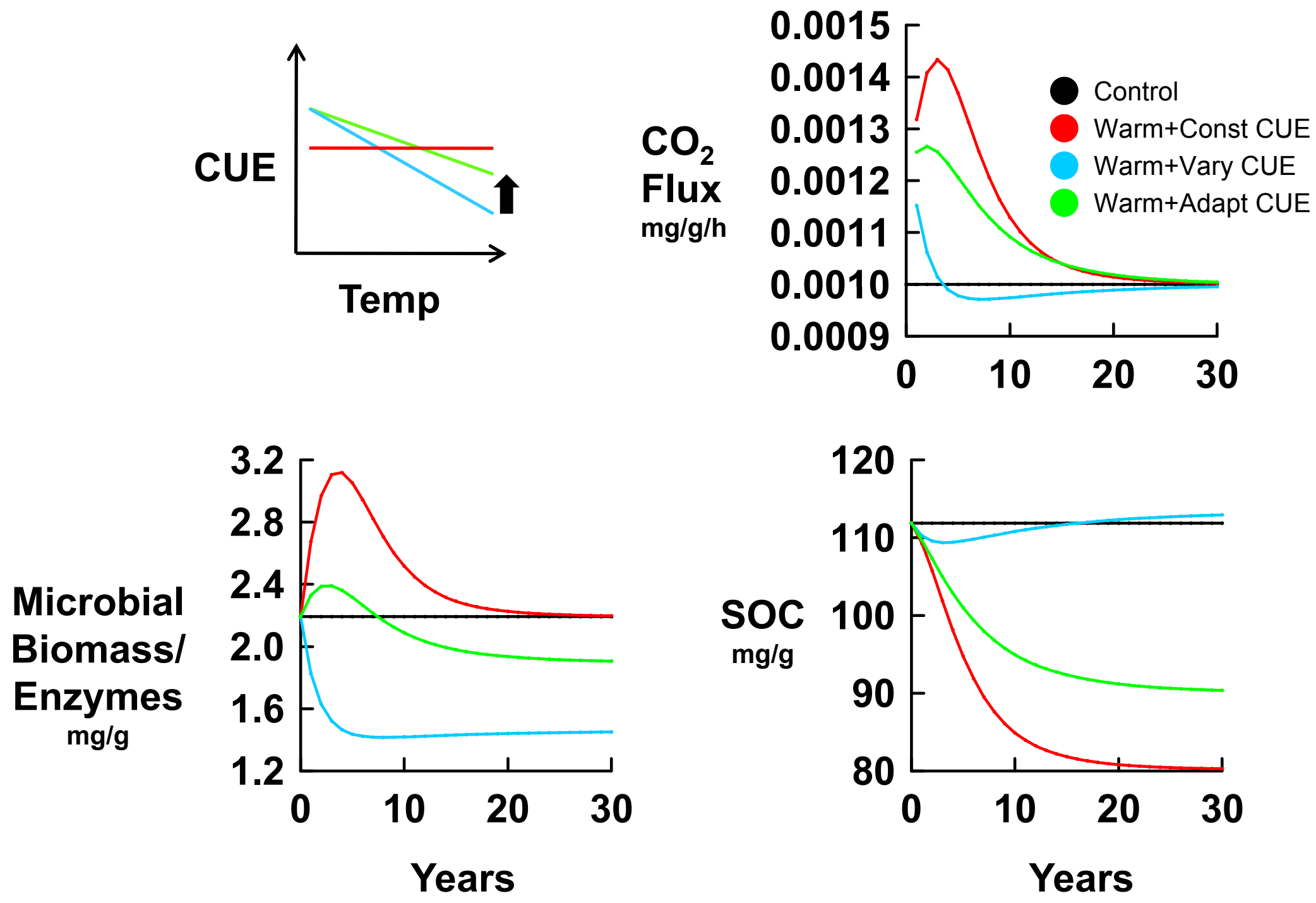


\section{Acclimation of CUE restores losses}

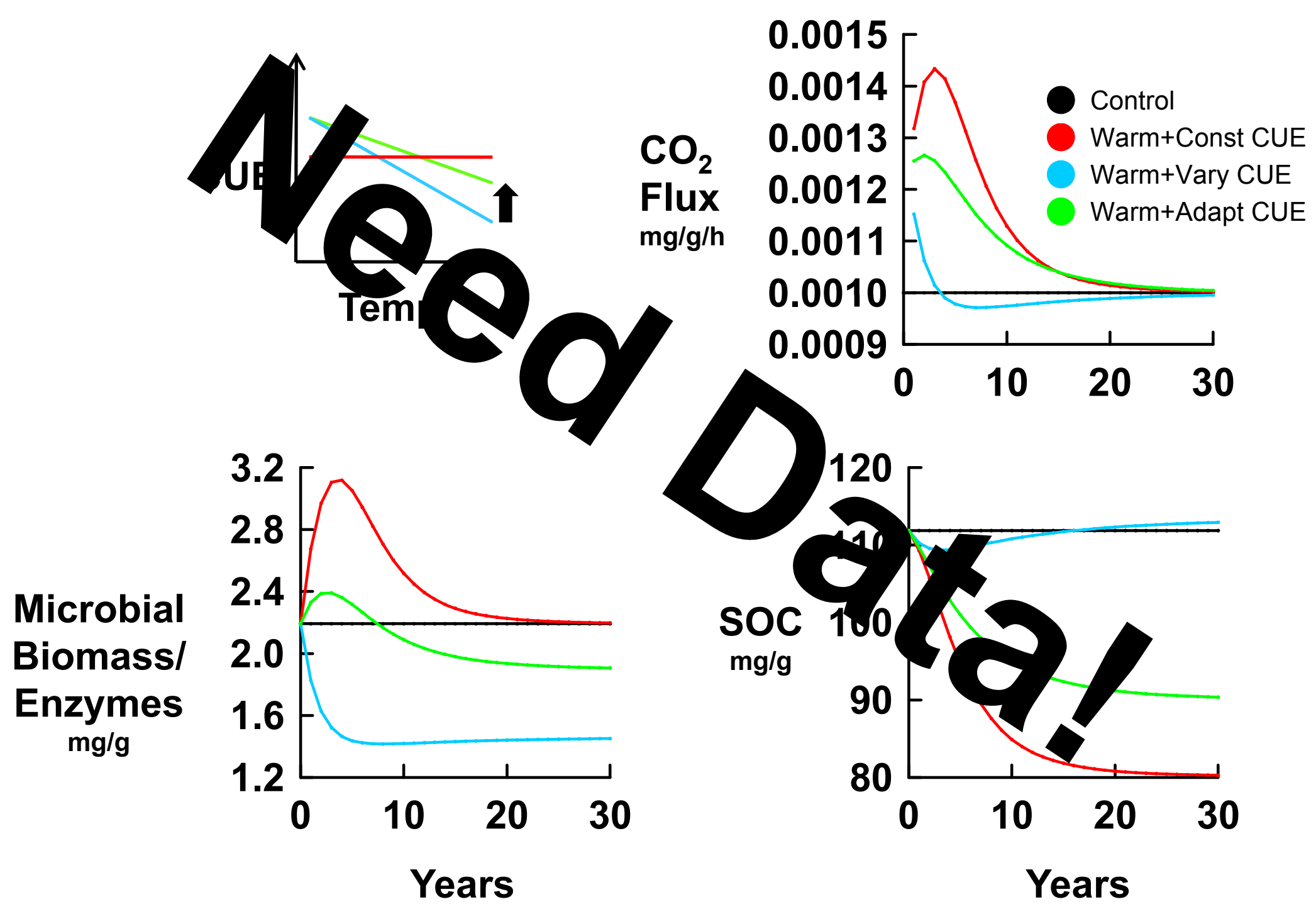




\section{Temperature constraints}

- Can we explain ephemeral $\mathrm{CO}_{2}$ response to warming (e.g. Melillo et al. 2002)

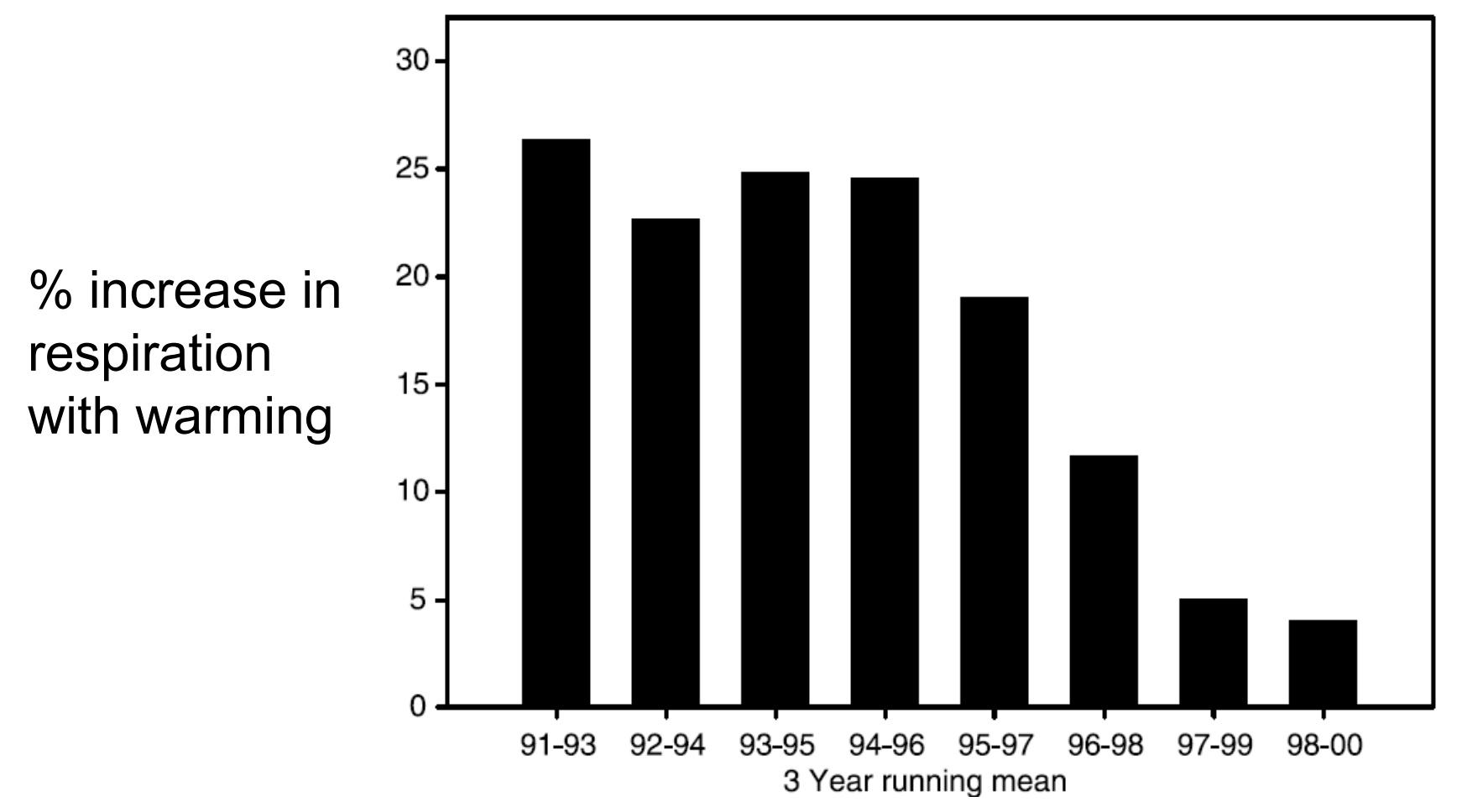




\section{Hypotheses}

- Substrate depletion: $\mathrm{CO}_{2}$ respiration returns to control levels because SOC pools are depleted

- Thermal adaptation (or acclimation): microbial physiological parameters change in a way that reduces $\mathrm{CO}_{2}$ respiration 


\section{A lesson from dynamic vegetation models}

- DGVMs incorporate plant functional types

- Mechanistic representation of ecosystem processes like photosynthesis

- Aggregation based on leaf traits, growth form, and phenology e.g. "deciduous broadleaf trees"
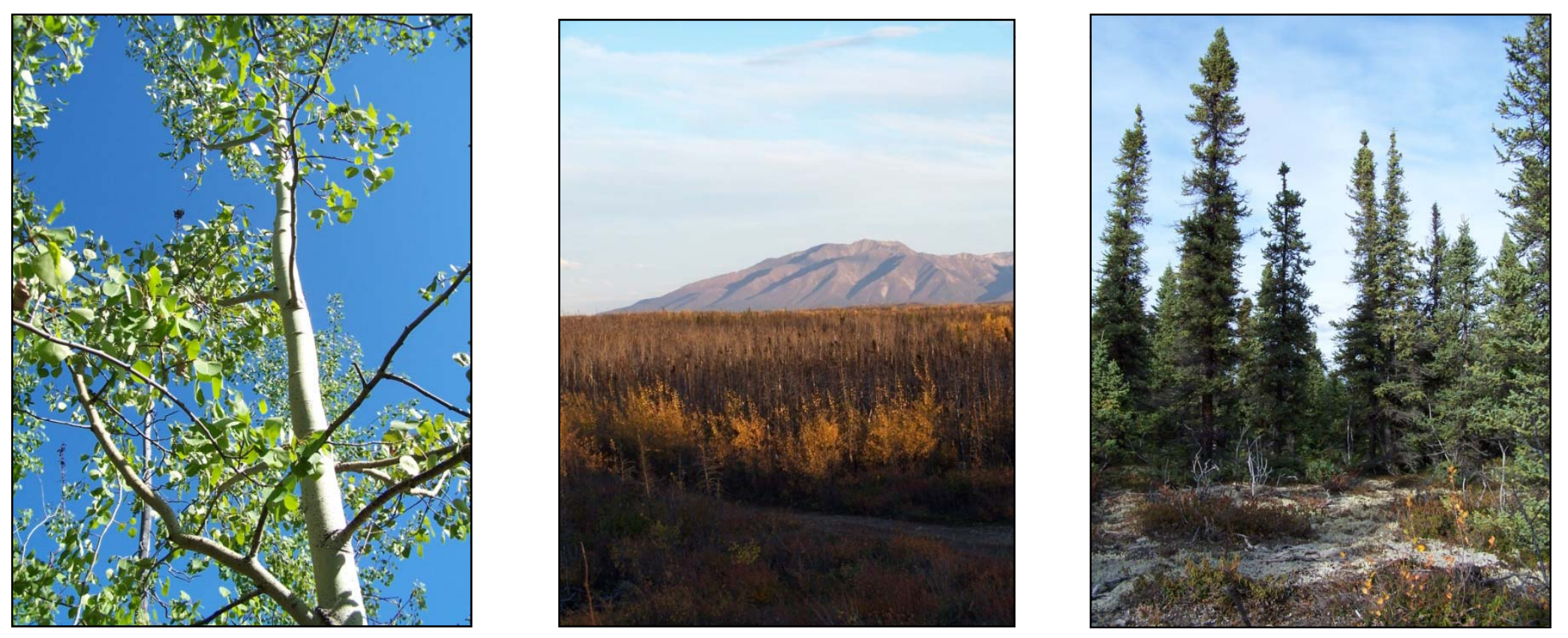


\section{Taxonomic aggregation}

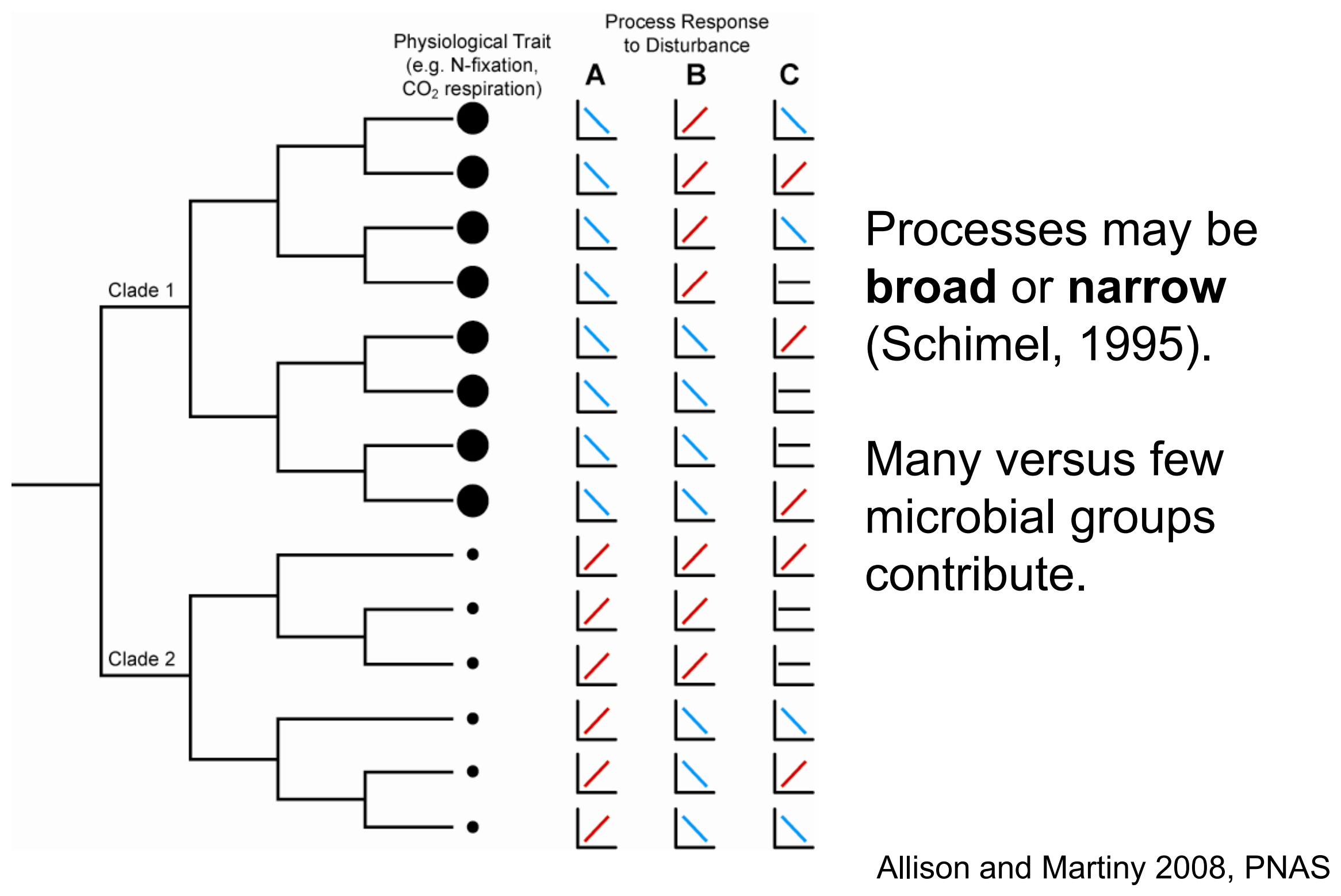




\section{Trait-based aggregation also possible}

(e.g. Moorhead and Sinsabaugh 2006)

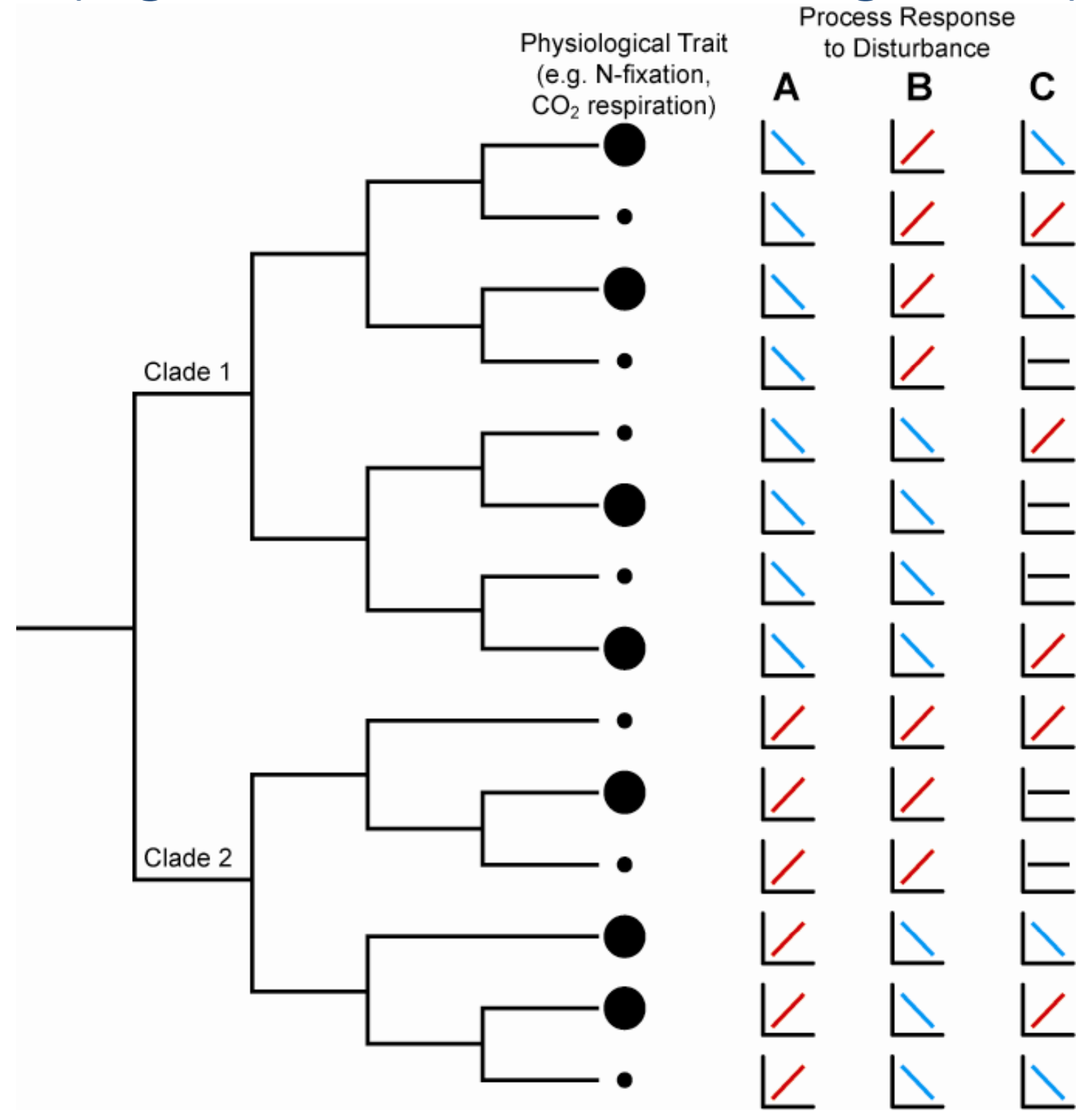




\section{Wednesday, August 4, 2010 - 4:05 PM}

\section{SYMP 13-8: Integrating microbial community data with ecological theory}

Steven D. Allison, University of California, Irvine

\section{Background/Question/Methods}

Molecular and bioinformatics techniques are revealing the rich diversity of microbial communities. These approaches generate valuable data that ecologists could use to develop and test theories that apply to a large fraction of living organisms. However, the complexity of microbial community data is a challenge to achieving this integration. A fundamental question in microbial ecology is how to aggregate microbial communities so that their taxa may be represented in theoretical models. Recently, models based on microbial traits have been developed to tackle this question. Such models may represent microbial taxa as functional groups or stochastic assemblages with a distribution of trait values. Here, I define these two model types and show how they can be used to make predictions about the function of complex microbial communities. I focus on organic matter decomposition and nutrient mineralization because this function is typically driven by complex microbial communities.

\section{Results/Conclusions}

When applying ecological theory to predict rates of organic matter turnover, complex communities can be aggregated based on relevant traits, such as the ability to produce extracellular enzymes. Ecological and evolutionary theories provide a framework for predicting the distribution of these traits across time and space. For example, theories on ecological succession may predict the temporal progression of enzyme traits that occur in association with a decomposing substrate. Dispersal parameters from island biogeography theory may determine the movement of enzyme traits across the microbial landscape. Evolutionary theory can be used to predict the appearance and loss of enzyme traits due to selective pressures in microbial ecosystems. All of these theories then determine the abundance of particular functional groups, or the means and variances of trait distributions that directly affect ecological function. Functional group models may be useful in simple systems, but stochastic models based on distributions may be more relevant for complex communities with a diversity of continuous traits and many unidentified members. 